\title{
PENGEMBANGAN SISTEM REKOMENDASI MENU PAKET MEETING MENGGUNAKAN METODE FP-GROWTH (STUDI KASUS LOTUS GARDEN HOTEL KEDIRI)
}

\author{
Dwi Puspitasari ${ }^{1}$, Deasy Sandhya Elya Ikawati ${ }^{2}$, Betlian Fajrin ${ }^{3}$ \\ 1, 2, 3 Teknik Informatika, Teknologi Informasi, Politeknik Negeri Malang \\ ${ }^{1}$ dwi.puspitasari@polinema.ac.id, ${ }^{2}$ deasysandhya@polinema.ac.id, ${ }^{3}$ fajrinbetlian@ gmail.com
}

\begin{abstract}
Abstrak
Perkembangan teknologi informasi yang semakin pesat, menuntut pihak manajemen hotel agar para konsumen mendapatkan informasi secara cepat dan akurat mengenai sarana dan prasarana yang disediakan. Namun, tidak tersedianya informasi mengenai detil menu paket meeting yang dapat diambil ketika konsumen menyewa ruang pertemuan (meeting) serta bagaimana cara pemesanannya. Dalam hal ini, untuk memperoleh informasi yang benar mengenai penyewaan ruang dan detil menu paket meeting yang dapat dipesan tidak terlepas dari proses penggalian dan pengolahan data transaksi penyewaan ruang. Dari data transaksi menu yang diperoleh dapat pula dimanfaatkan untuk mengetahui pola beli konsumen agar dapat diketahui pola-pola yang sering muncul (frequent pattern) sehingga dapat dibuat menjadi suatu rekomendasi menu paket meeting agar memudahkan konsumen dalam menentukan menu paket meeting yang dipilih. Salah satu algoritma yang dapat digunakan untuk mencari himpunan data yang sering muncul dalam suatu kumpulan data adalah algoritma FP-Growth. Algoritma FP-Growth merupakan algoritma yang digunakan untuk mendapatkan pola dari sebuah basis data. Pada penelitian ini, nilai ambang batas (threshold) yang ditetapkan sebesar $=3$, sehingga diperoleh aturan-aturan yang kemudian diambil beberapa aturan (rule) dengan nilai final support dan final confidence tertinggi untuk ditarik suatu kesimpulan yaitu nilai kekuatan keterkaitan antar item paling tinggi 11.0 yang diuji menggunakan metode lift ratio. Juga untuk pengujian kesesuaian aturan yang dihasilkan dari perhitungan manual dan perhitungan dari system sebesar 57\%.
\end{abstract}

Kata kunci : Rekomendasi Menu Paket Meeting, FP-Growth, Final Support, Final Confidence

\section{Pendahuluan}

Perkembangan teknologi informasi yang semakin pesat, menuntut pihak manajemen hotel untuk terus melakukan pembaruan agar bisnisnya tetap diminati oleh konsumen. Pembaruan tersebut akan membantu para konsumen untuk mendapatkan informasi secara cepat dan akurat mengenai sarana dan prasarana yang disediakan oleh pihak manajemen hotel.

Ketersediaan informasi yang akurat tidak terlepas dari proses penggalian dan pengolahan data. Data - data yang melimpah dari hasil proses penggalian sejatinya memiliki potensi untuk dapat dimanfaatkan untuk mengetahui pola beli konsumen terhadap barang atau untuk mencari set item yang sering muncul dalam suatu set transaksi (market basket analysis), sehingga dapat diketahui pola - pola yang sering muncul (frequent pattern) dengan menganalisa data transaksi.

Frequent pattern adalah salah satu alternatif algoritma yang dapat digunakan untuk menentukan himpunan data yang paling sering muncul (frequent itemset) dalam sebuah kumpulan data [1]. Frequent pattern growth (FP-Growth) adalah salah satu alternatif algoritma dari metode asosiasi yang dapat digunakan untuk menentukan himpunan data yang paling sering muncul (frequent itemset) dalam sebuah kumpulan data.

Strategi pembaruan dalam era teknologi informasi ini juga telah diterapkan oleh salah satu hotel berbintang di kota Kediri, Jawa Timur yaitu Lotus Garden Hotel yang telah memiliki sebuah website untuk memberikan informasi kepada para konsumen. Namun, di dalam website tersebut tidak menyediakan informasi mengenai detil paket dan menu makanan yang dapat di ambil ketika konsumen ingin menyewa salah satu fasilitas ruangan yang telah disediakan yang dapat digunakan untuk acara pertemuan (meeting) serta bagaimana cara pemesanannya.

Dari penjelasan latar belakang di atas, peneliti tertarik untuk mengangkat permasalahan yang ada di dalam sistem Lotus Garden Hotel. Permasalahan tersebut digunakan sebagai penelitian tugas akhir / skripsi oleh penulis dengan judul "Pengembangan Sistem Rekomendasi Menu Paket Meeting Menggunakan Algoritma FP-Growth". Dengan adanya pengembangan dari sistem tersebut diharapkan dapat membantu merekomendasikan menu paket meeting yang tepat bagi para konsumen. 


\section{Landasan Teori}

\subsection{Sistem Rekomendasi}

Sistem rekomendasi adalah suatu program yang melakukan prediksi sesuatu item, seperti rekomendasi film, musik, buku, berita dan lain sebagainya yang menarik user. Sistem ini berjalan dengan mengumpulkan data dari user secara langsung maupun tidak [2].

Pengumpulkan data secara langsung dapat dilakukan sebagai berikut:

a. Meminta user untuk melakukan rating pada sebuah item.

b. Meminta user untuk melakukan rangking pada item favorit setidaknya memilih satu item favorit.

c. Memberikan beberapa pilihan item pada user dan memintanya memilih yang terbaik.

d. Meminta user untuk mendaftar item yang paling disukai atau item yang tidak disukainya.

Pengumpulan data dengan tidak langsung berhubungan dengan seorang user, dilakukan dengan cara seperti berikut:

a. Mengamati item yang dilihat oleh seorang user pada sebuah web e-commerce.

b. Mengumpulkan data transaksi pada sebuah toko online.

\subsection{Paket Meeting}

Meeting sudah menjadi kewajiban yang harus dilakukan setiap perusahaan / instansi. Banyak hotel dan office tower yang sudah menyediakan meeting room yang dapat di pesan dengan meals dan coffe break, atau disebut dengan Paket Meeting. Lotus Garden Hotel Kediri juga menyediakan paket - paket meeting yang dapat di pesan oleh konsumen. Di dalam paket - paket meeting tersebut terdapat fasilitas fasilitas diantaranya venue, perlengkapan untuk meeting (LCD proyektor, white screen, note pad, alat tulis, sound system, mic) dan paket - paket menu makanan diantaranya paket teratai, paket bougenville, paket anggrek, paket lotus serta menu coffe break.

\subsection{Frequent Pattern}

Frequent Patterns adalah pola yang sering terjadi di dalam data. Ada banyak jenis dari frequent patterns, termasuk di dalamnya pola, sekelompok itemset, sub-sequence, dan sub-struktur. Sebuah frequent patterns biasanya mengacu pada satu itemset yang sering muncul bersama-sama dalam suatu kumpulan data transaksional [3].

\subsection{Association Rule Mining}

Assosiation rules mining digunakan untuk mencari hubungan korelasi atau asosiasi antar item pada sebuah set data. Analisis asosiasi dikenal sebagai salah satu teknik data mining yang menjadi dasar dari berbagai teknik data mining lainnya. Support (nilai penunjang) yaitu persentase kombinasi item tersebut dalam database. Seperti yang terdapat pada persamaan 1 .

$\operatorname{Support}(\mathrm{A})=\frac{\sum(\text { Transaksi item } A)}{\sum(\text { Transaksi })}$

Confidence (nilai kepastian) merupakan rasio antara jumlah transaksi yang di dalamnya terdapat item-item yang ada dalam aturan asosiasi, dengan jumlah transaksi yang di dalamnya terdapat item yang ada dalam kondisi asosiatif [4]. Seperti yang terdapat pada persamaan 2 .

Confidence $\mathrm{P}(\mathrm{B} \mid \mathrm{A})=\frac{\sum(\text { Transaksi item } A \text { dan } B)}{\sum(\text { Transaksi } A)}$

\subsection{Algoritma FP-Growth}

FP-Growth merupakan salah satu algoritma yang termasuk dalam association rule mining. Algoritma FP-Growth dibagi menjadi tiga langkah yaitu:

a. Tahap pembangkitan Conditional Pattern Base Conditional Pattern Base merupakan sub database yang berisi prefix path (lintasan prefix) dan suffix pattern (pola akhiran). Pembangkitan conditional pattern base didapatkan melalui FPtree yang telah dibangun sebelumnya.

b. Tahap pembangkitan Conditional FP-tree Pada tahap ini support count dari setiap item pada setiap conditional pattern base dijumlahkan, lalu setiap item yang memiliki jumlah support count $>=$ minimum support count akan dibangkitkan dengan conditional FP-tree.

c. Tahap pencarian frequent itemset apabila Conditional FP-tree merupakan lintasan tunggal (single path), maka didapatkan frequent itemset dengan melakukan kombinasi item untuk setiap conditional FPtree. Jika bukan lintasan tunggal, maka dilakukan pembangkitan FP-Growth secara rekursif [4].

\section{Metodologi}

\subsection{Pengumpulan Data}

Metode pengambilan data yang penulis gunakan adalah metode wawancara dan studi lapangan. Di dalam wawancara, penulis menemui salah seorang karyawan di bidang marketing di Lotus Garden Hotel Kediri. Pada saat melakukan wawancara, penulis diberikan gambaran mengenai bagaimana alur penyewaan ruang pertemuan (meeting) serta apa saja fasilitas yang diberikan ketika konsumen menyewa salah satu ruang tersebut. Kemudian pada saat studi lapangan, penulis mendapatkan data berupa file excel dari bulan Januari 
2016 hingga Desember 2018 yang berisi data transaksi penyewaan ruang.

\subsection{Pengolahan Data}

Didalam pengolahan data pada penelitian ini, penulis memberikan beberapa penjelasan untuk bisa mendapatkan hasil analisa data yang maksimal, diantaranya adalah sebagai berikut:

1. Data yang akan di proses adalah data transaksi penyewaan ruang pertemuan berupa file excel. (Data pada bulan Januari 2017).

2. Setelah didapatkan data yang bersih, data tersebut akan di transformasi untuk lebih memudahkan dalam pembuatan tree. Transformasi dilakukan pada data total pax dan total revenue.

3. Data transaksi bulan Januari 2017 setelah dilakukan proses transformasi terhadap data total pax dan total revenue.

Tabel 1. Data Transaksi Setelah Transformasi

\begin{tabular}{|c|c|c|c|c|c|c|c|}
\hline $\begin{array}{l}\text { kin } \\
\text { d of } \\
\text { eve } \\
\text { nt }\end{array}$ & $\begin{array}{l}\text { ti } \\
\text { me } \\
\text { fro } \\
\text { m }\end{array}$ & $\begin{array}{l}\text { ti } \\
\text { m } \\
\text { e } \\
\text { to }\end{array}$ & $\begin{array}{l}\text { to } \\
\text { tal } \\
\text { pa } \\
\mathbf{x} \\
\end{array}$ & $\begin{array}{l}\text { tota } \\
\text { l } \\
\text { rev } \\
\text { enu } \\
\text { e }\end{array}$ & $\begin{array}{l}\text { menu } \\
1\end{array}$ & menu 2 & $\begin{array}{l}\text { menu } \\
3\end{array}$ \\
\hline $\begin{array}{l}\text { mee } \\
\text { ting }\end{array}$ & $\begin{array}{l}08^{\prime} \\
00\end{array}$ & $\begin{array}{l}1 \\
6 \\
0 \\
0\end{array}$ & P1 & A1 & $\begin{array}{l}\text { ayam } \\
\text { kalasa } \\
\mathrm{n}\end{array}$ & $\begin{array}{l}\text { tumis } \\
\text { buncis } \\
\text { sambal } \\
\text { krecek }\end{array}$ & $\begin{array}{l}\text { mie } \\
\text { saus } \\
\text { lada } \\
\text { hitam }\end{array}$ \\
\hline $\begin{array}{l}\text { mee } \\
\text { ting }\end{array}$ & $\begin{array}{l}08^{\prime} \\
00\end{array}$ & $\begin{array}{l}1 \\
6 \\
0 \\
0 \\
\end{array}$ & $\mathrm{P} 1$ & A1 & $\begin{array}{l}\text { ayam } \\
\text { bakar } \\
\text { kecap }\end{array}$ & $\begin{array}{l}\text { buncis } \\
\text { kentang } \\
\text { pedas }\end{array}$ & $\begin{array}{l}\text { mie } \\
\text { goren } \\
\text { g jawa }\end{array}$ \\
\hline $\begin{array}{l}\text { mee } \\
\text { ting }\end{array}$ & $\begin{array}{l}08^{\prime} \\
00\end{array}$ & $\begin{array}{l}1 \\
6 \\
0 \\
0 \\
\end{array}$ & $\mathrm{P} 1$ & A1 & $\begin{array}{l}\text { ayam } \\
\text { bakar } \\
\text { kecap }\end{array}$ & $\begin{array}{l}\text { buncis } \\
\text { kentang } \\
\text { pedas }\end{array}$ & $\begin{array}{l}\text { mie } \\
\text { goren } \\
\text { g jawa }\end{array}$ \\
\hline $\begin{array}{l}\text { mee } \\
\text { ting }\end{array}$ & $\begin{array}{l}08^{\prime} \\
00 \\
\end{array}$ & $\begin{array}{l}1 \\
6 \\
0 \\
0 \\
\end{array}$ & $\mathrm{P} 1$ & A1 & $\begin{array}{l}\text { ayam } \\
\text { kalasa } \\
\mathrm{n} \\
\end{array}$ & $\begin{array}{l}\text { ayam } \\
\text { bakar } \\
\text { kecap }\end{array}$ & $\begin{array}{l}\text { mie } \\
\text { saus } \\
\text { lada } \\
\text { hitam } \\
\end{array}$ \\
\hline $\begin{array}{l}\text { par } \\
\text { enti } \\
\text { ng }\end{array}$ & $\begin{array}{l}07 \\
00\end{array}$ & $\begin{array}{l}1 \\
3 \\
0 \\
0 \\
\end{array}$ & P6 & A4 & $\begin{array}{l}\text { sup } \\
\text { ayam } \\
\text { jamur }\end{array}$ & $\begin{array}{l}\text { ayam } \\
\text { pramba } \\
\text { nan }\end{array}$ & $\begin{array}{l}\text { perked } \\
\text { el cabe } \\
\text { ijo }\end{array}$ \\
\hline $\begin{array}{l}\text { mee } \\
\text { ting }\end{array}$ & $\begin{array}{l}16^{\prime} \\
00 \\
\end{array}$ & $\begin{array}{l}2 \\
2 \\
0 \\
0 \\
\end{array}$ & $\mathrm{P} 1$ & A1 & $\begin{array}{l}\text { sup } \\
\text { ayam } \\
\text { jamur }\end{array}$ & $\begin{array}{l}\text { ayam } \\
\text { goreng } \\
\text { bawang }\end{array}$ & $\begin{array}{l}\text { pindan } \\
\text { g telur }\end{array}$ \\
\hline $\begin{array}{l}\text { mee } \\
\text { ting }\end{array}$ & $\begin{array}{l}10^{\prime} \\
00 \\
\end{array}$ & $\begin{array}{l}1 \\
5 \\
0 \\
0 \\
\end{array}$ & $\mathrm{P} 1$ & A1 & $\begin{array}{l}\text { rendan } \\
\text { g daun } \\
\text { singko } \\
\text { ng }\end{array}$ & $\begin{array}{l}\text { tahu } \\
\text { tempe } \\
\text { goreng }\end{array}$ & $\begin{array}{l}\text { ayam } \\
\text { laos }\end{array}$ \\
\hline $\begin{array}{l}\text { gat } \\
\text { heri } \\
\text { ng }\end{array}$ & $\begin{array}{l}18^{\prime} \\
00\end{array}$ & $\begin{array}{l}2 \\
2 \\
0 \\
0 \\
\end{array}$ & $\mathrm{P} 2$ & A3 & $\begin{array}{l}\text { sup } \\
\text { sehat }\end{array}$ & $\begin{array}{l}\text { nasi } \\
\text { goreng } \\
\text { merah }\end{array}$ & $\begin{array}{l}\text { ayam } \\
\text { bakar } \\
\text { dabu } \\
\text { dabu } \\
\end{array}$ \\
\hline $\begin{array}{l}\text { mee } \\
\text { ting }\end{array}$ & $\begin{array}{l}10^{\prime} \\
00 \\
\end{array}$ & $\begin{array}{l}1 \\
5 \\
0 \\
0 \\
\end{array}$ & $\mathrm{P} 1$ & A1 & $\begin{array}{l}\text { sup } \\
\text { sehat }\end{array}$ & $\begin{array}{l}\text { ayam } \\
\text { bakar } \\
\text { kecap }\end{array}$ & $\begin{array}{l}\text { tahu } \\
\text { tempe } \\
\text { bacem } \\
\end{array}$ \\
\hline $\begin{array}{l}\text { gat } \\
\text { heri } \\
\text { ng }\end{array}$ & $\begin{array}{l}08^{\prime} \\
00\end{array}$ & $\begin{array}{l}1 \\
5 \\
0 \\
0\end{array}$ & P4 & A6 & $\begin{array}{l}\text { sup } \\
\text { timlo }\end{array}$ & $\begin{array}{l}\text { ayam } \\
\text { pramba } \\
\text { nan }\end{array}$ & $\begin{array}{l}\text { balado } \\
\text { telur }\end{array}$ \\
\hline $\begin{array}{l}\text { sem } \\
\text { inar }\end{array}$ & $\begin{array}{l}10^{\prime} \\
00\end{array}$ & $\begin{array}{l}1 \\
6 \\
\end{array}$ & $\mathrm{P} 1$ & A1 & $\begin{array}{l}\text { banana } \\
\text { bread }\end{array}$ & $\begin{array}{l}\text { mineral } \\
\text { water }\end{array}$ & $\begin{array}{l}\text { risol } \\
\text { mayo }\end{array}$ \\
\hline
\end{tabular}

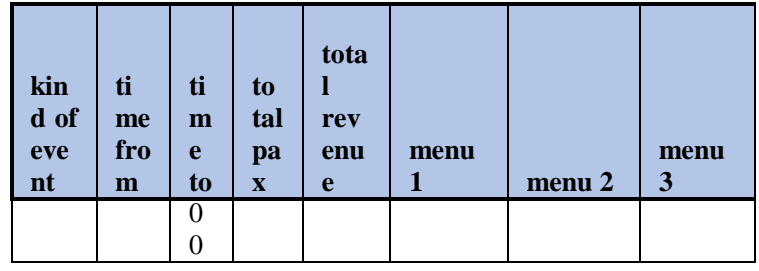

Tabel 1 berisi data yang didalamnya telah terdapat data yang telah ditransformasi sebelumnya dan data tersebut siap di olah menggunakan algoritma FP-Growth.

4. Kemudian dicari frekuensi kemunculan tiap item (frequent item) dengan ditetapkan nilai ambang batas $($ threshold $)=3$. Semakin tinggi nilai ambang batas (threshold) yang ditetapkan, maka jumlah frekuensi kemunculan tiap itemset (frequent item) semakin kecil. Sehingga akan mempengaruhi kombinasi item yang akan dihasilkan setelah dilakukan pengolahan data transaksi menggunakan algoritma FP-Growth.

5. Telah ditetapkan sebelumnya bahwa nilai threshold (ambang batas) $=3$. Sehingga item yang nilai frekuensi kemunculannya $<3$ akan dihapus. Berikut merupakan tabel kemunculan item dengan threshold.

6. Kemudian didapatkan data transaksi ter order.

Tabel 2. Data Transaksi Ter Order

\begin{tabular}{|c|c|c|c|c|c|c|c|}
\hline $\begin{array}{l}\text { kind } \\
\text { of } \\
\text { even } \\
t\end{array}$ & $\begin{array}{l}\text { tim } \\
\text { e } \\
\text { fro } \\
\text { m }\end{array}$ & $\begin{array}{l}\mathrm{ti} \\
\mathrm{m} \\
\mathrm{e} \\
\text { to }\end{array}$ & $\begin{array}{l}\text { tot } \\
\text { al } \\
\text { pa } \\
x\end{array}$ & $\begin{array}{l}\text { total } \\
\text { reve } \\
\text { nue }\end{array}$ & $\begin{array}{l}\text { menu } \\
1\end{array}$ & $\begin{array}{l}\text { menu } \\
2\end{array}$ & $\begin{array}{l}\text { menu } \\
3\end{array}$ \\
\hline $\begin{array}{l}\text { meet } \\
\text { ing }\end{array}$ & $\begin{array}{l}08^{\prime} \\
00\end{array}$ & $\begin{array}{l}16 \\
10 \\
0\end{array}$ & $\mathrm{P} 1$ & A1 & & & \\
\hline $\begin{array}{l}\text { meet } \\
\text { ing }\end{array}$ & $\begin{array}{l}08^{\prime} \\
00 \\
\end{array}$ & $\begin{array}{l}16 \\
10 \\
0 \\
\end{array}$ & $\mathrm{P} 1$ & A1 & $\begin{array}{l}\text { ayam } \\
\text { bakar } \\
\text { kecap }\end{array}$ & & $\begin{array}{l}\text { mie } \\
\text { goren } \\
\text { g } \\
\text { jawa } \\
\end{array}$ \\
\hline $\begin{array}{l}\text { meet } \\
\text { ing }\end{array}$ & $\begin{array}{l}08^{\prime} \\
00 \\
\end{array}$ & $\begin{array}{l}16 \\
10 \\
0 \\
\end{array}$ & $\mathrm{P} 1$ & A1 & $\begin{array}{l}\text { ayam } \\
\text { bakar } \\
\text { kecap }\end{array}$ & & $\begin{array}{l}\text { mie } \\
\text { goren } \\
\text { g } \\
\text { jawa }\end{array}$ \\
\hline $\begin{array}{l}\text { meet } \\
\text { ing }\end{array}$ & $\begin{array}{l}08^{\prime} \\
00 \\
\end{array}$ & $\begin{array}{l}16 \\
10 \\
0 \\
\end{array}$ & $\mathrm{P} 1$ & A1 & & $\begin{array}{l}\text { ayam } \\
\text { bakar } \\
\text { kecap }\end{array}$ & \\
\hline $\begin{array}{l}\text { meet } \\
\text { ing }\end{array}$ & & & $\mathrm{P} 1$ & A1 & & & \\
\hline $\begin{array}{l}\text { meet } \\
\text { ing }\end{array}$ & & & $\mathrm{P} 1$ & A1 & & & \\
\hline $\begin{array}{l}\text { meet } \\
\text { ing }\end{array}$ & & & $\mathrm{P} 1$ & A1 & & $\begin{array}{l}\text { ayam } \\
\text { bakar } \\
\text { kecap }\end{array}$ & \\
\hline & & & $\mathrm{P} 1$ & A1 & & $\begin{array}{l}\text { miner } \\
\text { al } \\
\text { water }\end{array}$ & \\
\hline
\end{tabular}

Tabel 2 merupakan tabel yg berisi transaksi terorder. Artinya setelah dilakukan proses pencarian frekuensi kemunculan item, item - item yang nilai 
kemunculannya kurang dari ambang batas (threshold) akan di hapus dari tabel data transaksi. Sehingga di dalam tabel tersebut banyak terdapat kolom yang kosong. Kemudian didapatkan tabel data transaksi terorder yang siap di bentuk menjadi FP tree.

7. Proses pembentukan FP tree.
a. Tree setelah TID ke-1

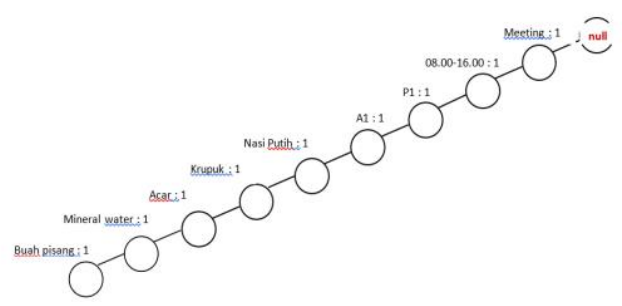

Gambar 1. Tree TID ke-1

Gambar 1 merupakan tree yang telah dibentuk berdasarkan transaksi ID ke 1 atau transaksi baris pertama dari dalam tabel data transaksi terorder.

\section{b. Tree setelah TID ke-11}

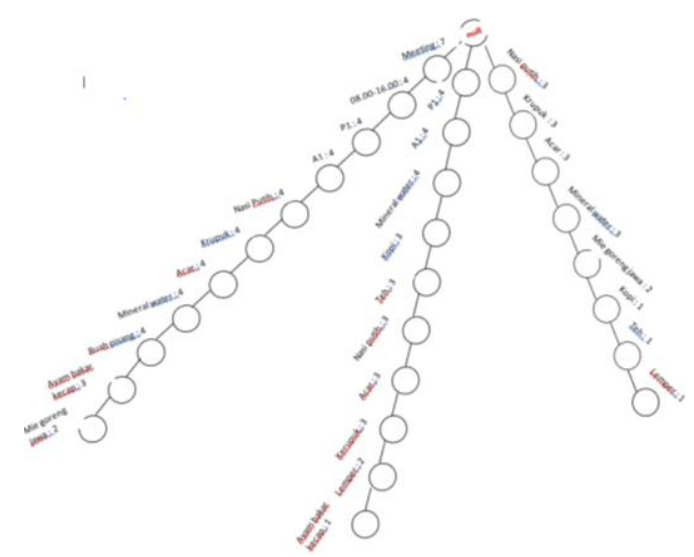

Gambar 2. Tree TID ke-11

Gambar 2 merupakan tree yang telah dibentuk berdasarkan transaksi ID ke 11 atau transaksi baris terakhir dari dalam tabel data transaksi terorder.

8. Tahap conditional pattern base. Pada tahap ini, cari tree dengan suffix (akhiran) dari frequent itemset sesuai urutan frequent list yang paling kecil jumlah kemunculannya. Diantaranya lintasan yang mengandung mineral water, nasi putih, krupuk, acar, A1, P1, meeting, 08'00 16'00, buah pisang, ayam bakar kecap, mie goreng jawa, kopi, tea dan lemper.

9. Tahap conditional FP tree. Pada tahap ini nilai item pada tree yang kurang dari nilai threshold akan dihapus.

10. Berikut merupakan table frequent itemset, yang didapatkan dari tahap conditional fp-tree.

Tabel 3. Frequent Itemset

\begin{tabular}{|l|l|}
\hline \multicolumn{1}{|c|}{ SUFFIX } & \multicolumn{1}{c|}{ FREQUENT ITEMSET } \\
\hline Tea & $\{\mathrm{P} 1 ; \mathrm{Tea}\}$ \\
\hline Kopi & $\{\mathrm{P} 1 ;$ Kopi $\}$ \\
\hline Buah pisang & $\{$ Meeting; Buah pisang $\}$ \\
\hline
\end{tabular}

\begin{tabular}{|l|l|}
\hline \multicolumn{1}{|c|}{ SUFFIX } & \multicolumn{1}{|c|}{ FREQUENT ITEMSET } \\
\hline $\begin{array}{l}\text { Ayam bakar } \\
\text { kecap }\end{array}$ & $\{$ Meeting;Ayam Bakar Kecap $\}$ \\
\hline 08 '00-16'00 & $\{$ Meeting;08'00-16'00 $\}$ \\
\hline Meeting & $\{$ Meeting $\}$ \\
\hline $\mathrm{P} 1$ & $\{$ Meeting;P1 $\{$ P1 $\}$ \\
\hline A1 & $\{$ Meeting;A1 $\}\{\mathrm{P} 1 ; \mathrm{A} 1\}$ \\
\hline Nasi putih & $\begin{array}{l}\{\text { Meeting;Nasi putih }\}\{\mathrm{P} 1 ; \text { Nasi putih }\} \\
\{\text { Nasi putih }\}\end{array}$ \\
\hline Krupuk & $\begin{array}{l}\{\text { Meeting; Krupuk }\}\{\mathrm{P} 1 ; \text { Krupuk }\}\{\text { Nasi } \\
\text { putih;Krupuk }\}\end{array}$ \\
\hline Acar & $\begin{array}{l}\{\text { Meeting;Acar }\}\{\mathrm{P} 1 ; \text { Acar }\}\{\text { Nasi } \\
\text { putih;Acar }\}\end{array}$ \\
\hline $\begin{array}{l}\text { Mineral } \\
\text { water }\end{array}$ & $\begin{array}{l}\{\text { Meeting; Mineral water }\}\{\mathrm{P} 1 ; \text { Mineral } \\
\text { water }\} \text { Nasi putih;Mineral water }\}\end{array}$ \\
\hline
\end{tabular}

Tabel 3 menampilkan frequent itemset atau kombinasi item yang paling sering muncul dalam data transaksi.

11. Kemudian hitung nilai support dan confidence dari masing - masing itemset.

Tabel 4. Contoh Perhitungan Support dan Confidence

\begin{tabular}{|ll}
\hline Support $(\mathrm{P} 1 ; \mathrm{Tea})$ & $=$ Count $(\mathrm{P} 1 ; \mathrm{Tea})$ \\
& $/$ Jumlah Transaksi \\
$=$ & $3 / 11=0.27=27 \%$ \\
Confidence $(\mathrm{P} 1 ; \mathrm{Tea})$ & $=$ Count $(\mathrm{P} 1 ; \mathrm{Tea}) /$ Count $(\mathrm{P} 1)$ \\
$=$ & $3 / 8=0.375=37.5 \%$
\end{tabular}

Tabel 4 menunjukkan contoh perhitungan nilai support dan confidence dari data transaksi bulan Januari 2017 menggunakan persamaan 1.

Selanjutnya dilakukan contoh perhitungan untuk mencari final support dan confidence. Yaitu dengan cara mengalikan antara nilai support dan confidence masing - masing item. Setelah diketahui, maka dapat ditarik kesimpulan kombinasi item yang paling sering muncul.

Jika diberikan nilai minimal support sebesar $36 \%$ dan minimal confidence sebesar 57\% maka nilai paling tinggi adalah $20.556 \%$. Sehingga aturan yang paling kuat adalah jika seseorang mengadakan event Meeting pada jam 08'00 - 16'00 dengan total pax P1 dan biaya A1, maka orang tersebut akan memesan menu Nasi putih, Krupuk, Acar, Mineral water dan Buah pisang.

\subsection{Metode Pengujian}

Untuk menguji keberhasilan system pada penelitian ini menggunakan pengujian lift ratio. Lift ratio adalah suatu ukuran untuk mengetahui kekuatan aturan asosisasi (association rule) yang telah terbentuk. Nilai lift ratio biasanya digunakan sebagai penentu apakah aturan asosiasi valid atau tidak valid [5].

Apabila hasil dari pengujian rule menggunakan lift ratio menghasilkan nilai lebih dari 1,00 maka rule tersebut dapat dijadikan acuan dalam rekomendasi menu makanan dalam penelitian ini. 


\subsection{Deskripsi Sistem}

Aplikasi ini merupakan aplikasi pengembangan sistem rekomendasi menu paket meeting untuk membantu konsumen dalam menentukan menu makanan. Di dalam aplikasi tersebut konsumen dapat memasukkan nilai (value) yang akan diolah oleh algoritma FP-Growth, diantaranya:

a. Jenis kegiatan

b. Total pax

c. Total revenue

d. Time to

e. Time from

Setelah konsumen memasukkan nilai - nilai tersebut konsumen harus menekan tombol "pesan" yang terdapat di dalam sistem aplikasi, sehingga sistem akan dapat melakukan proses perhitungan menggunakan algoritma FP-Growth yang menghasilkan keluaran berupa aturan-aturan (rules). Dari rules tersebut akan didapatkan rekomendasi menu makanan yang sesuai untuk konsumen yang ditampilkan pada halaman yang berbeda. Pada halaman itu pula konsumen dapat memilih, apakah ingin menggunakan menu rekomendasi hasil perhitungan atau menu yang dapat dipilih secara manual. Selanjutnya, konsumen harus menekan tombol "simpan pesanan" agar pesanan dapat diverifikasi oleh admin dari sitem aplikasi tersebut dan selanjutnya diproses sesuai prosedur manajemen hotel.

\subsection{Analisis Sistem}

Dalam penelitian ini akan dilakukan analisa terhadap kebutuhan system berdasarkan alur kerjanya. Untuk lebih detilnya dapat dilihat pada gambar 3.

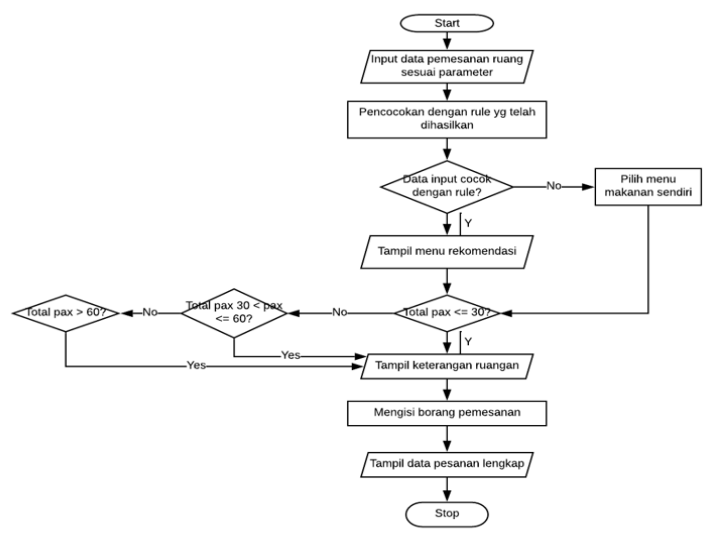

Gambar 3. Alur Sistem

Pada gambar 3, ketika konsumen menggunakan aplikasi ini maka pada halaman pertama akan terdapat menu pemesanan yang berisi form pemesanan ruangan yang harus di isi terlebih dahulu oleh konsumen. Di dalam form tersebut, berisi beberapa kolom yang harus di isi diantaranya kolom jenis kegiatan, total pax, total revenue, time from, time to, dan tanggal. Kemudian konsumen harus menekan tombol "pesan" agar system dapat melakukan pencocokan inputan dengan rule yang telah dihitung sebelumnya. Pencocokan dilakukan hanya pada data jenis kegiatan, time from, time to dan total revenue. Jika data inputan tidak menemukan kecocokan dengan rule, maka konsumen harus terlebih dahulu memilih menu makanan sendiri agar proses selanjutnya dapat berjalan. Sedangkan, jika data yg diinputkan sesuai dengan rule yang dihasilkan, maka kemudian akan dilakukan pencocokan terhadap data inputan total pax dengan data total pax yang ada di dalam database. Kemudian, jika total pax yang di pesan $<=30$, maka akan digunakan ruangan lain yang mempunyai kapasitas lebih besar. Saat sudah didapatkan ruangan yang kosong, maka akan ditampilkan data pesanan lengkap bersama dengan menu makanan yang telah direkomendasikan atau di pilih sendiri. Selanjutnya, konsumen harus menekan tombol "simpan pesanan" agar data pemesanan dapat diterima oleh admin dari system aplikasi. Setelah itu, konsumen harus mengikuti prosedur pemesanan selanjutnya yang telah ditentukan oleh pihak manajemen hotel.

\subsection{Implementasi Antar Muka}

Implementasi antar muka berisi tentang tampilan antar muka sistem yang telah dirancang pada bab sebelumnya. Implementasi antar muka meliputi tampilan halaman user, dan tampilan halaman admin.

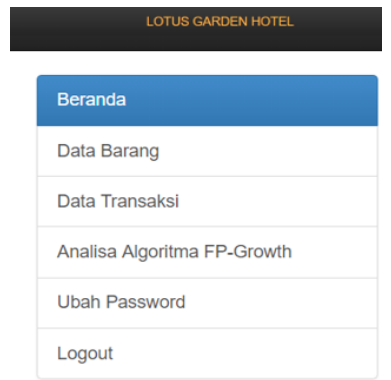

Gambar 4. Tampilan Menu Admin

Pada gambar 4 menunjukkan menu - menu apa saja yang dapat di akses oleh admin. Diantaranya menu data barang, data transaksi user, data transaksi excel, dan Analisa algoritma fp-growth.

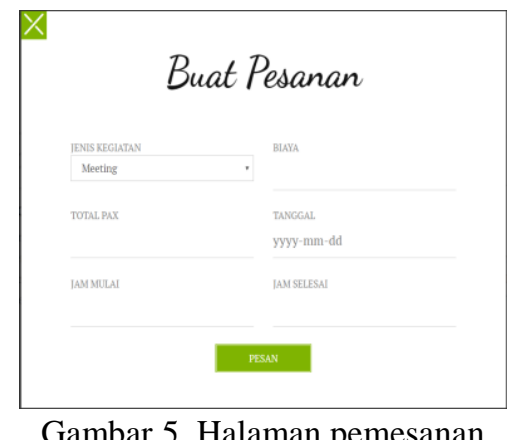

Gambar 5. Halaman pemesanan 
Gambar 5 merupakan tampilan form untuk user jika user hendak melakukan pemesanan ruang pertemuan. User harus melengkapi semua kolom yang tersedia agar inputan user dapat di proses oleh system

\subsection{Pengujian Fungsional}

Pengujian fungsional dilakukan untuk mengetahui apakah fitur-fitur dari sistem ini berjalan dengan semestinya atau tidak. Teknik yang digunakan dalam pengujian fungsional ini adalah teknik blackbox.

Berikut merupakan pengujian fungsional dari Analisa algoritma fp-growth.

Tabel 5. Pengujian Analisa Algoritma

\begin{tabular}{|l|l|}
\hline \multicolumn{2}{|c|}{ Hasil Pengujian } \\
\hline $\begin{array}{l}\text { Data } \\
\text { masukan }\end{array}$ & $\begin{array}{l}\text { Nilai minimal support, minimal confidence } \\
\text { dan jumlah transaksi }\end{array}$ \\
\hline $\begin{array}{l}\text { Hasil } \\
\text { pengujian }\end{array}$ & $\begin{array}{l}\text { Berhasil menghasilkan aturan / rule yang } \\
\text { digunakan sebagai acuan rekomendasi }\end{array}$ \\
\hline Screenshoot & $\begin{array}{l}\text { Analisa Algoritma FP-Growth } \\
\end{array}$ \\
& $\begin{array}{l}|c| \\
\text { Perhitungan }\end{array}$ \\
\hline Kesimpulan & Berhasil \\
\hline
\end{tabular}

Pada table 5 dilakukan pengujian terhadap fungsi analisa algoritma oleh admin. Dan didapatkan hasil bahwa fungsi tersebut dapat berjalan dengan sesuai

\subsection{Pengujian Non-Fungsional}

Selain melakukan pengujian fungsionalitas system dilakukan juga pengujian algoritma, yaitu algoritma fp-growth. Pengujian dilakukan dengan menghitung kekuatan aturan asosiasi yang telah terbentuk.

\begin{tabular}{|l|c|c|c|}
\multicolumn{5}{|c|}{ Tabel 6. Pengujian Lift Ratio } \\
\hline \multicolumn{1}{|c|}{ Rules } & Conf. & NC & Lift Ratio \\
\hline $\begin{array}{l}\text { Meeting -> } \\
\text { Buah pisang }\end{array}$ & 4 & 4 & 11.0 \\
\hline $\begin{array}{l}\text { Meeting -> } \\
\text { 08'00-16'00 }\end{array}$ & 4 & 4 & 11.0 \\
\hline Meeting -> A1 & 7 & 8 & 9.6 \\
\hline Meeting >> P1 & 7 & 8 & 9.6 \\
\hline $\begin{array}{l}\text { Meeting -> } \\
\text { Nasi putih }\end{array}$ & 7 & 10 & 7.7 \\
\hline $\begin{array}{l}\text { Meeting -> } \\
\text { Kerupuk -> }\end{array}$ & 7 & 10 & 7.7 \\
\hline $\begin{array}{l}\text { Meeting } \\
\text { Acar }\end{array}$ & 7 & 10 & 7.7 \\
\hline $\begin{array}{l}\text { Meeting -> } \\
\text { Mineral water }\end{array}$ & 7 & 11 & 7 \\
\hline
\end{tabular}

Pada tabel 6 dilakukan pengujian kekuatan aturan asosiasi yang terbentuk dengan menggunakan metode lift ratio. Jika perhitungan menghasilkan nilai lebih dari 1,00 maka dapat disimpulkan bahwa aturan yang dihasilkan dapat dijadikan acuan. Diketahui nilai tertinggi dari aturan yang terbentuk adalah $20.556 \%$.
Maka lift ratio yang dihitung adalah yang memiliki nilai aturan tertinggi dari 11 transaksi.

Kemudian setelah dilakukan perhitungan pada system dengam ambang $=3$ didapatkan aturan (rule), yang kemudian didapatkan tabel perbandingan rule menu makananan yang dihasilkan dari perhitungan menual dan perhitungan yang dilakukan oleh system sebagai berikut :

Tabel 7. Tabel Pengujian Sistem

\begin{tabular}{|l|l|c|c|}
\hline \multicolumn{1}{|c|}{ Rule 1 } & \multicolumn{1}{c|}{ Rule 2 } & Manual & Sistem \\
\hline Meeting & Nasi putih & $\sqrt{ }$ & $\sqrt{ }$ \\
\hline Meeting & $\begin{array}{l}\text { Mineral } \\
\text { water }\end{array}$ & $\sqrt{ }$ & $\sqrt{ }$ \\
\hline Meeting & Krupuk & $\sqrt{ }$ & $\sqrt{ }$ \\
\hline Meeting & Acar & $\sqrt{ }$ & $\sqrt{ }$ \\
\hline Meeting & Buah pisang & $\sqrt{ }$ & - \\
\hline Meeting & Kopi & - & $\sqrt{ }$ \\
\hline Meeting & Tea & - & $\sqrt{ }$ \\
\hline
\end{tabular}

Pada table 7, nilai persentasi kecocokan aturan yang dihasilkan dari perhitungan manual dan yang dihasilkan oleh system dihitung menggunakan persamaan 3 sebegai berikut:

$\%$ kecocokan $=\frac{\text { Jumlah aturan } \text { yang sama }}{\text { Jumlah keseluruhan aturan }} \times 100 \%$

Persentase kecocokan $=\frac{4}{7} \times 100 \%=57 \%$

Sehingga, untuk persentase kecocokan keseluruhan rule yaitu sebesar $57 \%$.

\section{Kesimpulan Dan Saran}

\subsection{Kesimpulan}

Setelah melakukan analisis, perancangan, implementasi beserta pengujian yang dilakukan, maka diharapkan dapat ditarik beberapa kesimpulan, yaitu:

1. Sistem ini di bangun dengan beberapa tahapan diantaranya identifikasi masalah, studi literatur, pengumpulan data, perancangan, implementasi dan testing. Dalam pengimplementasiannya, sistem ini menggunakan bahasa pemrograman PHP dan menggunakan database MySQL. Sistem ini mengolah data transaksi penyewaan ruang bulan Januari 2016 sampai bulan Desember 2018. Tahapan pengujian atau testing dilakukan dengan pengujian fungsionalitas system yang menggunakan Teknik blackbox dan pengujian menggunakan kekuatan aturan yg terbentuk menggunakan pengujian lift ratio.

2. Penerapan algoritma fp-growth untuk merekomendasikan menu paket meeting berdasarkan jenis kegiatan, waktu pelaksanaan (time to - time from), total pax dan total revenue dapat menghasilkan aturan (rule) yang keterkaitan antar itemnya kuat. Dibuktikan dengan nilai pada pengujian lift ratio yang menghasilkan nilai 11.0. Juga untuk pengujian aturan yang dihasilkan dari perhitungan manual 
dan perhitungan dari system didapatkan kecocokan sebesar $57 \%$.

\subsection{Saran}

Berdasarkan penelitian yang dilakukan, saran penulis untuk system ini lebih lanjut adalah system ini dapat diubah menjadi mobile application agar konsumen dapat dengan mudah mengaplikasikannya.

\section{Dafar Pustaka:}

[1] Kusrini,"Penerapan Algortima Apriori Pada Data Mining Untuk Mengelom- pokkan Barang Berdasarkan Kecenderungan Kemunculan Bersama Dalam Satu Transaksi”, E-learning Center STMIK AMIKOM Yogyakarta, 2007.

[2] Scafer, J.B, Konstan, J.A, dan Riedl, J, ItemBased Collaborative Filtering Recommender Algorithms, WWW10, 2001.

[3] Siregar, A. Mutoi, Puspabhuana, Adam, "DATA MINING: Pengolahan Data Menjadi Informasi dengan RapidMiner", CV Kekata Group, ISBN: 602547396X,9786025473968.

[4] Mahmudah, R. Ratih, Aribowo, Eko, "Penggunaan Algoritma FP-Growth Untuk Menemukan Aturan Asosiasi Pada Data Transaksi Penjualan Obat Di Apotek (Studi Kasus: Apotek Uad)", Jurnal Sarjana Teknik Informatika, Program Studi Teknik Informatika, Volume 2 Nomor 3, Oktober 2014, E-ISSN: 2338-5197.

[5] Fauzy, Mohammad, Kemas Rahmad Saleh W dan Asror, Ibnu "Penerapan Metode Association Rule Menggunakan Algoritma Apriori pada Simulasi Prediksi HUjan Wilayah Kota Bandung”, Jurusan Ilmiah Teknologi Informasi Terapan, Fakultas Informatika Telkom University, Volume II, No 2, 15 April 2016, ISSN : 2407 - 3911. 
Volume 6, Edisi 3, Mei 2020

$22 \mid \mathrm{H}$ a 1 a $\mathrm{m}$ a $\mathrm{n}$ 